Bài báo khoa học

\title{
Đánh giá kĩ năng dụ̣ báo mưa định lượng từ mô hình quy mô toàn cầu và khu vực phân giải cao cho khu vực Bắc Bộ
}

\author{
Nguyễn Thị Nga ${ }^{1}$, Công Thanh ${ }^{2}$, Mai Khánh Hưng ${ }^{1}$, Dư Đức Tiến ${ }^{*}$ * \\ ${ }^{1}$ Trung tâm Dự báo khí tượng thủy văn quốc gia; hongnga12897@gmail.com; \\ duductien@gmail.com; maikhanhhung18988@gmail.com \\ ${ }^{2}$ Khoa Khí tượng Thủy văn và Hải dương học, Đại học Khoa học Tự nhiên, ĐHQGHN; \\ congthanh1477@gmail.com \\ *Tác giả liên hệ: duductien@gmail.com; Tel.: +84-936067015
}

Ban Biên tập nhận bài: 13/7/2021; Ngày phản biện xong: 17/8/2021; Ngày đăng bài: $25 / 10 / 2021$

Tóm tắt: Nghiên cứu trình bày kết quả đánh giá dự báo mưa định lượng dựa trên mô hình toàn cầu IFS và mô hình khu vực phân giải cao (WRF-ARW) trong năm 2020. Bài báo giới thiệu chi tiết phương pháp đánh giá theo không gian dựa trên chỉ số kĩ năng FSS (Fractional Skill Score) sử dụng các số liệu mưa từ vệ tinh GSMaP và số liệu mưa trên lưới (thiết lập từ số liệu mưa ước lượng radar, vệ tinh và mưa tự động). Các chỉ số đánh giá kĩ năng (POD, BIAS, TS) theo phương pháp truyền thống được mở rộng theo từng phân cấp mưa chi tiết kết hợp biểu đồ đánh giá kĩ năng tổng hợp (performance diagram) trên các vị trị trạm của khu vực nghiên cứu (Bắc Bộ). Các kết quả cho thấy kĩ năng dự báo định lượng cho khu vực Bắc Bộ còn thấp. Mặc dù vậy, mô hình phân giải cao kết hợp đồng hóa số liệu (3DVAR) đã tăng được kĩ năng dự báo ở các ngưỡng mưa lớn $(>50 \mathrm{~mm} / 24 \mathrm{~h})$ trong hạn 1-3 ngày, qua đó cho phép bổ sung thông tin mang tính chất định lượng-cực trị bên cạnh sản phẩm dự báo của mô hình IFS trong công tác dự báo nghiệp vụ mưa lớn.

Từ khóa: Đánh giá dự báo mưa theo không gian; chỉ số FSS; Phân cấp mưa.

\section{Mở đầu}

Với khả năng cung cấp các dự báo có tính định lượng, chi tiết về lượng mưa, phân bố mưa, dự báo số trị (NWP) đã được sử dụng rộng rãi tại các trung tâm thời tiết trên thế giới nói chung và tại Việt Nam trong vấn đề dự báo định lượng mưa QPF (Quantitative Precipitation Forecast). Trong những năm trở lại đây, phương pháp NWP đã cho phép mở rộng không những cả về hạn dự báo mà còn tăng cường chất lượng dự báo các hoàn lưu khí quyển và hiện tượng, hệ quả thời tiết một cách định lượng ở các quy mô không gian khác nhau, từ các mô hình toàn cầu độ phân giải ngang $15-50 \mathrm{~km}$ đến các mô hình quy mô vừa $(<15 \mathrm{~km})$ và dưới vừa $(<2 \mathrm{~km})$. Tuy nhiên, QPF của NWP vẫn chứa đựng nhiều sai số lớn và việc ứng dụng trực tiếp giá trị mưa định lượng từ dự báo của mô hình trên các khu vực nhiệt đới và gió mùa còn hạn chế. Một trong những nguyên nhân chính dẫn đến sai số trong dự báo mưa của mô hình là các biến giáng thủy trong mô hình đều là dạng dẫn xuất (diagnostic), được xác định và tính toán từ các biến dự báo khác trong mô hình. Do đó, các sơ đồ vật lý của mô hình chỉ có thể chính xác tại một số khu vực trên thế giới khi có các quan trắc để hiệu chỉnh các tham số phù hợp [1]. Trong trường hợp các hiện tượng mưa lớn xảy ra với lượng lớn dị thường, mẫu quan trắc rất hạn chế sẽ dẫn tới không có khả năng hiệu chỉnh (tuning) để có được các bộ tham số phù hợp để tính toán dẫn xuất ra biến giáng thủy dự báo trong mô hình. Bên cạnh đó, tính không chắc chắn (uncertainty) của mô hình số trị và điều kiện ban đầu, quá trình vật lý 
phi tuyến và tính bất định của khí quyển chưa được mô hình mô số mô phỏng chính xác nên vẫn còn sai khác giữa kết quả dự báo và quan trắc trong thực tế [2].

Tại Việt Nam, đã có nhiều công trình nghiên cứu về dự báo mưa cũng như đánh giá dự báo định lượng mưa từ mô hình toàn cầu [3-4] và các mô hình số trị độ phân giải cao [5-6]. Các nghiên cứu cho thấy kết quả dự báo mưa từ mô hình số trị, đặc biệt là các mô hình độ phân giải cao ngày càng được cải thiện. Ngoài ra, phương pháp đồng hóa-ứng dụng số liệu quan trắc đã có nhằm nâng cao chất lượng của dự báo ngày càng được quan tâm nghiên cứu. Các nghiên cứu thử nghiệm đồng hóa sử dụng số liệu radar [7], số liệu vệ tinh và số liệu quan trắc truyền thống [8] cho kết quả dự báo tốt hơn đáng kể khi chưa có đồng hóa số liệu. Hiện nay, Trung tâm Dự báo khí tượng Thủy văn (KTTV) quốc gia đã và đang khai thác, vận hành 2 lớp sản phẩm mồ hình dự báo gồm sản phẩm dự báo qui mô toàn cầu và sản phẩm dự báo số qui mô khu vực (hệ thống mô hình khu vực độ phân giải cao và hệ thống đồng hóa số liệu). Với sự phong phú về mặt sản phẩm và ưu điểm của từng loại mô hình việc xem xét đánh giá chất lượng kết quả dự báo của từng loại mô hình là thật sự cần thiết. Trong khuôn khổ bài báo sẽ tiến hành đánh giá chất lượng dự báo mưa của một số mô hình trên khu vực Bắc Bộ trong năm 2020. Nghiên cứu sẽ đưa ra các kết quả đánh giá dựa trên việc tính toán các chỉ số kĩ năng chi tiết theo khoảng phân cấp mưa (ví dụ trong khoảng $25-50 \mathrm{~mm} / 24 \mathrm{~h}$ ) và theo ngưỡng mưa (ví dụ lớn hơn $25 \mathrm{~mm} / 24 \mathrm{~h}$ ) thực hiện thống kê tại các trạm quan trắc Synop (đánh giá trên trạm) và thực hiện thống kê trên lưới bao phủ toàn bộ Bắc Bộ (đánh giá theo không gian). Thông tin về nguồn số liệu và mô hình cùng phương pháp đánh giá được trình bày chi tiết trong phần 2 của bài báo. Các kết quả và kết luận chung được đưa ra lần lượt tại mục 3 và 4 .

\section{Phương pháp nghiên cứu}

\subsection{Khu vục nghiên cứu}

Nghiên cứu thực hiện đánh giá sự cải thiện dự báo mưa định lượng cho Bắc Bộ trong giai đoạn từ tháng 4 đến tháng 12 năm 2020 . Khu vực nghiên cứu được giới hạn từ $19.5^{\circ} \mathrm{N}$ đến $23.5^{\circ} \mathrm{N}$ và $102^{\circ} \mathrm{E}$ đến $108.5^{\circ} \mathrm{E}$. Tổng số trạm đo mưa thuộc Bắc Bộ được sử dụng trong tính toán là 88 trạm bao gồm các trạm trên đất liền và các trạm đảo, trong đó: 22 trạm vùng Tây Bắc, 26 trạm vùng Việt Bắc, 25 trạm vùng Đông Bắc và 15 trạm vùng Đồng bằng Bắc Bộ. Hình 1 thể hiện phân bố theo không gian của 88 trạm nói trên và phạm vi khu vực nghiên cứu.

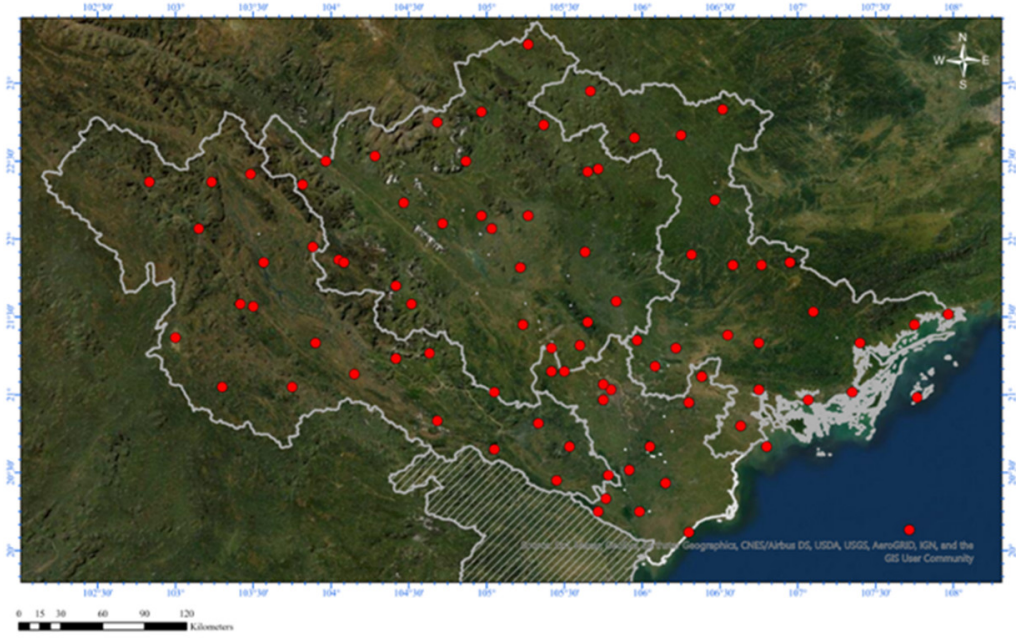

Hình 1. Phân bố theo không gian của 88 trạm đo mưa bề mặt và phạm vi khu vực nghiên cứu.

\subsection{Số liệu quan trắc mưa}

Nghiên cứu sử dụng số liệu quan trắc mưa từ hệ thống mạng lưới Synop trên khu vực Bắc Bộ (88 trạm được thể hiện chi tiết vị trí trên Hình 1). Ngoài ra là số liệu quan trắc bổ sung 
khác từ quan trắc mưa tự động (nguồn Dự án và nguồn xã hội hóa) và từ sản phẩm ước lượng mưa trên lưới của radar và vệ tinh [9]. Từ năm 2020, bộ số liệu mưa trên lưới đã được thiết lập từ mưa trạm và mưa ước lượng từ độ phản hồi của các trạm radar và vệ tinh cho mức độ chi tiết theo chiều ngang là $1 \mathrm{~km} \times 1 \mathrm{~km}$, được Đài khí tượng cao không thiết lập và truyền về Trung tâm Dự báo KTTV quốc gia với tần suất 1 tiếng một lần [10]. Bên cạnh đó là nguồn dữ liệu mưa ước lượng trên lưới của Nhật Bản $(\mathrm{GSMaP})$ với độ phân giải theo chiều ngang là $10 \mathrm{~km} \times 10 \mathrm{~km}[11]$.

\subsection{Số liệu mô hình dụ báo}

\subsubsection{Mô hình toàn cầu IFS của ECMWF}

Bên cạnh các mô hình toàn cầu GSM của Cơ quan khí tượng Nhật Bản (JMA) và GFS của Trung tâm Dự báo môi trường quốc gia Hòa Kỳ (NCEP), được sự đầu tư của Bộ Tài Nguyên và Môi Trường, từ cuối năm 2011 Trung tâm Dự báo KTTV quốc gia đã thu nhận dữ liệu dự báo gốc từ Trung tâm Dự báo hạn vừa Châu Ầu (ECMWF) với độ phân giải theo chiều ngang $14 \mathrm{~km}$ cho mô hình tất định IFS (Integrated Forecasting System) và $28 \mathrm{~km}$ cho hệ thống dự báo tổ hợp, hạn dự báo đến 10 ngày. Hiện tại, độ phân giải của IFS xấp xỉ $9 \mathrm{~km}$ và đây là một trong những mô hình qui mô toàn cầu có độ tin cậy cao nhất về dự báo các yếu tố khí tượng hiện nay theo hầu hết các nghiên cứu và đánh giá trên thế giới [12].

\subsubsection{Mô hình khu vực WRF-ARW và hệ thống đồng hóa số liệu biến phân 3 chiều}

Ngoài các hệ thống mô hình khu vực trước đây ứng dụng tại Trung tâm Dự báo KTTV quốc gia như HRM, COSMO của Cơ quan khí tượng liên bang Đức (DWD), mô hình WRF-ARW đã được ứng dụng trong nghiệp vụ từ năm 2005 (trong hệ thống dự báo tổ hợp hạn ngắn SREPS, độ phân giải $16 \mathrm{~km}$ ). Trong khuôn khổ Dự án "Tăng cường hệ thống dự báo thời tiết và cảnh báo sớm" do Ngân hàng thế giới tài trợ, hệ thống tính toán đã được nâng cấp lên siêu máy tính CrayXC40 từ cuối năm 2018, mô hình WRF-ARW phiên bản 3.9.1.1 đã được thiết lập chạy nghiệp vụ với độ phân giải ngang là $3 \mathrm{~km} \times 3 \mathrm{~km}$ sử dụng điều kiện biên từ mô hình IFS (độ phân giải $9 \mathrm{~km}$ ) với miền tính bao phủ toàn bộ lãnh thổ Việt Nam và Biển Đông, thời gian tích phân dự báo hạn 72 giờ sử dụng toàn bộ năng lực của hệ thống $(\sim 70-80$ Tflops) hết 45 phút, mô hình được kí hiệu là WRF3kmIFS [12].

Từ đầu năm 2020, Trung tâm Dự báo KTTV quốc gia đã triển khai chạy nghiệp vụ trên siêu máy tính CrayXC40 hệ thống đồng hóa số liệu 3DVAR (ĐHSL) cho mô hình WRF-ARW (độ phân giải $3 \mathrm{~km}$, điều kiện biên từ mô hình ECMWF). Sai số mô hình để đưa vào hệ thống ĐHSL sử dụng phương pháp NMC tính toán từ các dự báo phân giải cao trên toàn bộ lãnh thổ Việt Nam và Biển Đông (mẫu thống kê ít nhất trong 3 tháng) [12]. Các số liệu được sử dụng trong quá trình đồng hóa bao gồm: các số liệu quan trắc bề mặt và thám không vô tuyến của Việt Nam, các số liệu quan trắc trên thế giới bao gồm: Vệ tinh cực (NOAA, METOP, số liệu bức xạ phổ), quan trắc gió vệ tinh bề mặt (SCAT) và trên cao $(\mathrm{AMV})$, quan trắc từ các phương tiện thuyền bè của các nước khác (hệ thống GTS). Mô hình WRF3kmIFS có ĐHSL được kí hiệu là WRF3kmIFS-DA.

Khả năng tăng mức độ chi tiết trong dự báo định lượng của các mô hình phân giải cao kết hợp ĐHSL được thể hiện tại Hình 2 bằng kết quả so sánh giữa quan trắc mưa tích lũy $24 \mathrm{~h}$ xảy ra trên khu vực Bắc Bộ (khu vực Hà Giang $>350-400 \mathrm{~mm} / 24 \mathrm{~h}$ ) vào tháng 7/2020 và dự báo từ các mô hình IFS ( $<60 \mathrm{~mm} / 24 \mathrm{~h})$, WRF3kmIFS ( $>150 \mathrm{~mm} / 24 \mathrm{~h})$ và WRF3kmIFS-DA (>180 m/24h). Nguyên nhân gây ra mưa cục bộ cực trị tại vùng núi phía Bắc liên quan đến sự hội tụ gió giữa gió đông nam từ rìa áp cao cận nhiệt đới và gió tây nam và khu vực xảy ra mưa phụ thuộc nhiều vào vị trí dịch chuyển của rìa áp cao cận nhiệt đới. Các mô hình đều xác định khu vực miền Bắc nằm ở rìa lưỡi áp cao cận nhiệt đới, tuy nhiên việc thể hiện sự hội tụ gió trên khu vực Bắc Bộ trong trường phân tích và dự báo từ WRF3kmIFS-DA tốt hơn cho phép hiện tượng mưa phù hợp hơn so với mô hình IFS và mô hình phân giải cao chưa có ĐHSL. 
Phân tích thêm các kết quả của mô hình phân giải cao có ĐHSL được đưa ra trong Hình 2 đối với các trường gió của mô hình tại mực $500 \mathrm{hPa}$. Trên khu vực Bắc Bộ, quá trình ĐHSL đã giảm độ lớn thành phần gió kinh hướng $(\mathrm{Ua}-\mathrm{Uf}<0)$ và tăng độ lớn thành phần gió vĩ hướng $(\mathrm{Va}-\mathrm{Vf}>0)$ ứng với trường véc tơ gia số $\{\mathrm{Ua}-\mathrm{Uf}, \mathrm{Va}-\mathrm{Vf}\}$ tồn tại một dạng xoáy thuận kéo theo việc hướng gió tây nam trên khu vực Bắc Bộ có xu thế lệch sang phía Tây hơn và tăng mức độ hội tụ kinh hướng với rìa của cao áp cận nhiệt. Minh hoạ này cho thấy rõ những tác động của ĐHSL lên trường động lực của mô hình có khả năng tác động đến kết quả dự báo trong trường hợp mưa lớn cụ thể này.

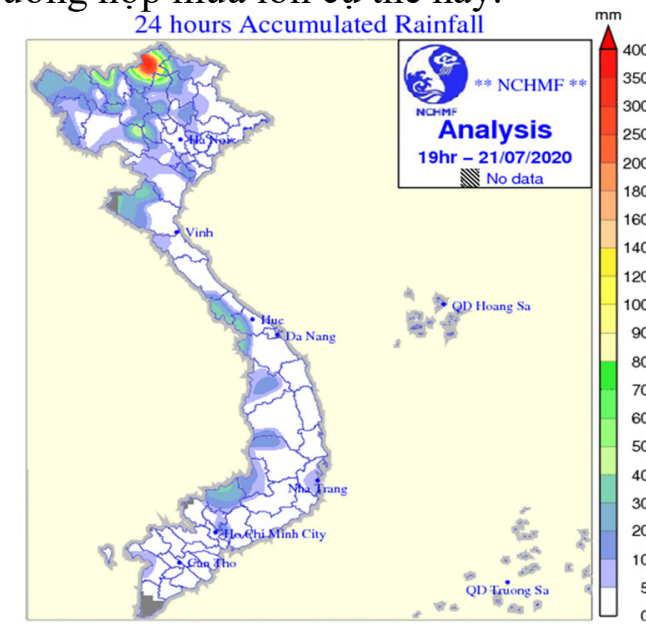

(a)

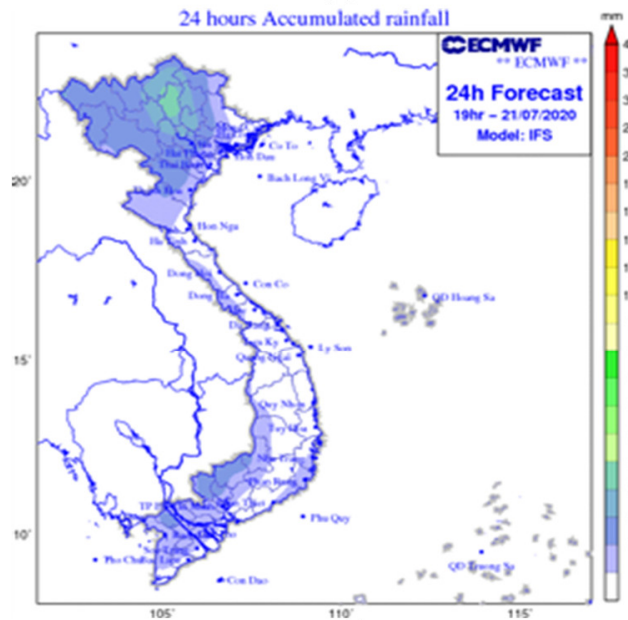

(c)

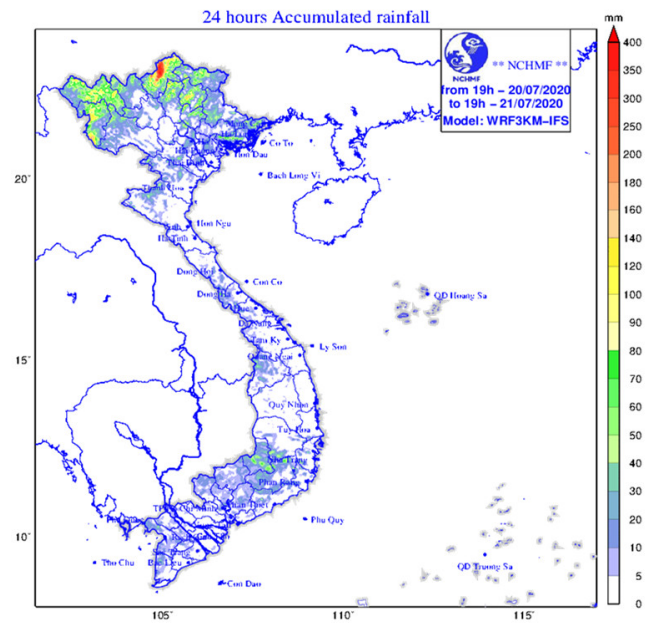

(e)

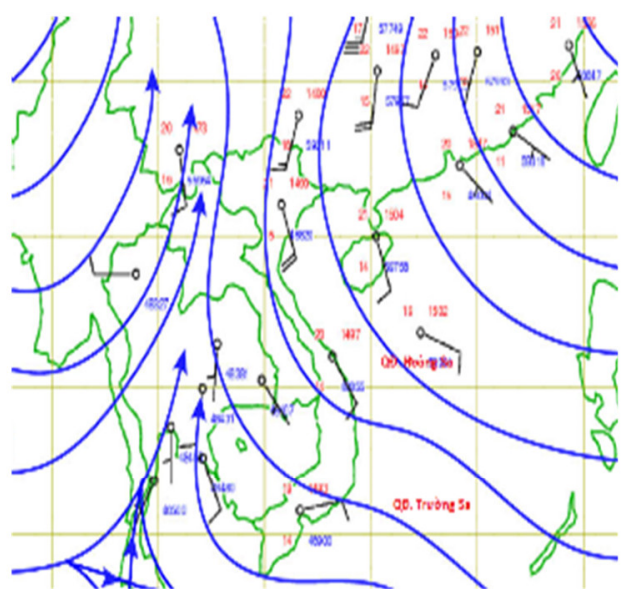

(b)

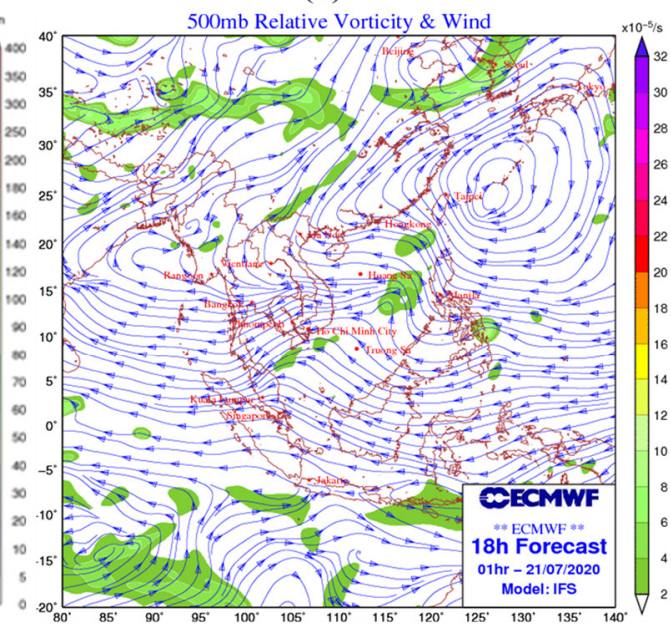

(d)

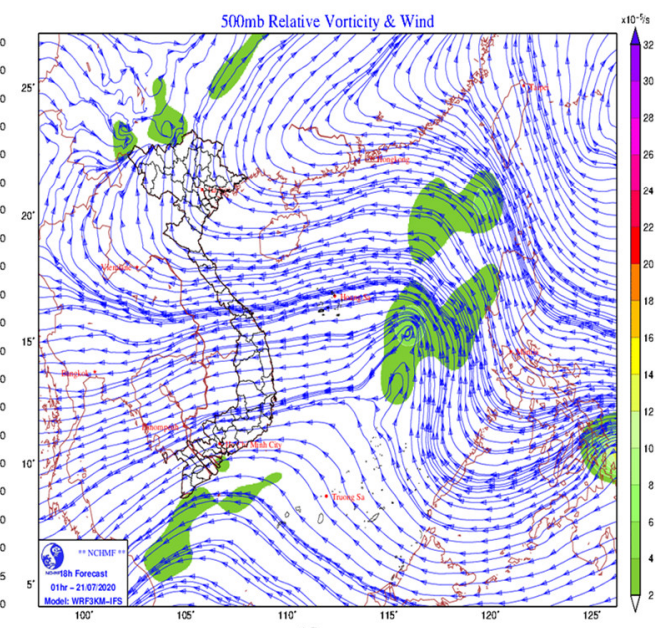

(f) 

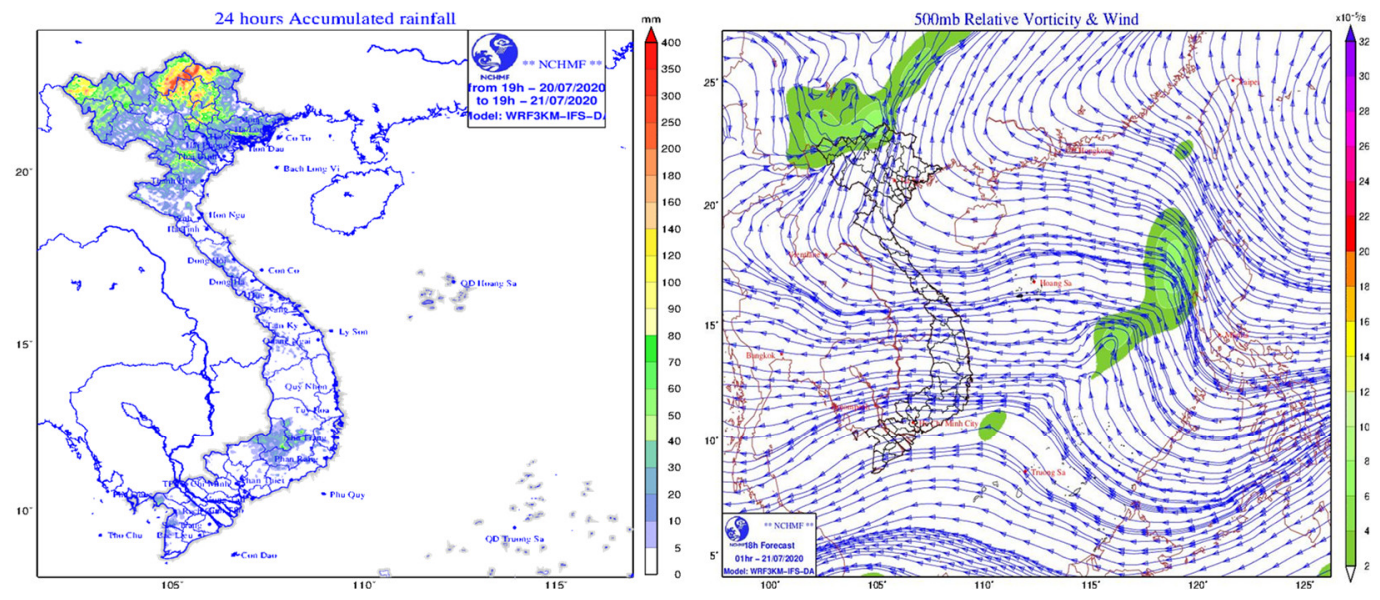

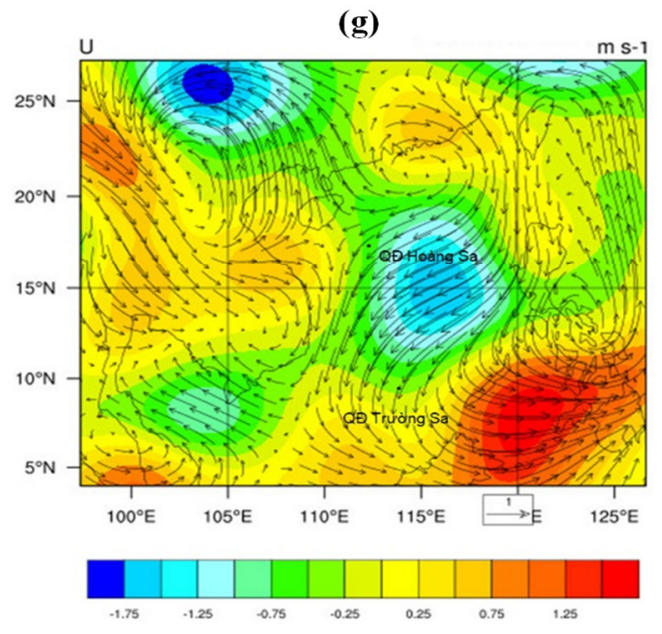

(i)

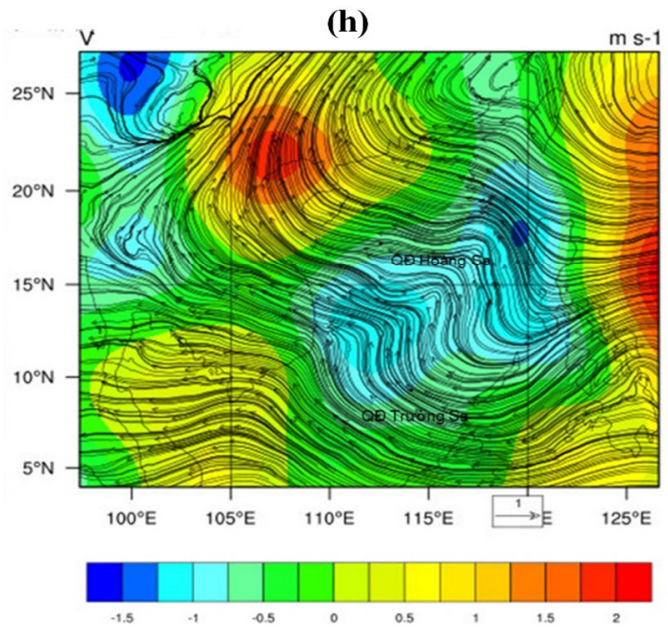

(j)

Hình 2. (a) Bản đồ mưa quan trắc từ $19 \mathrm{~h}$ ngày $20-21 / 7 / 2020$, (b) bản đồ đường dòng lúc $19 \mathrm{~h}$ ngày 21/7/2020, bản đồ dự báo mưa và đường dòng, xoáy tương đối mực $500 \mathrm{hPa}$ từ $\mathrm{IFS}(\mathrm{c}, \mathrm{d})$, từ WRF3kmIFS $(\mathrm{e}, \mathrm{f})$ và từ WRF3kmIFS-DA $(\mathrm{g}, \mathrm{h})$, (i) Trường gia số thay đổi (increment) giữa trường phân tích ban đầu $\mathrm{f}$ và trường phân tích tối ưu $\mathrm{a}$ bằng ĐHSL của thành phần gió $\mathrm{U}$ và trường gió gia số với thành phần là $\{\mathrm{Ua}-\mathrm{Uf}, \mathrm{Va}-\mathrm{Vf}\}$ tại mực $500 \mathrm{hPa}$ và $(\mathrm{j})$ Trường gia số thay đổi (increment) giữa trường phân tích ban đầu $\mathrm{f}$ và trường phân tích tối ưu a bằng ĐHSL của thành phần gió $\mathrm{V}$ và hàm dòng gió ban đầu tại mực 500hPa.

Thời điểm dự báo của các mô hình số trị được sử dụng để đánh giá là lúc 00UTC hằng ngày. Trước khi thực hiện quá trình đánh giá dự báo, các dữ liệu quan trắc mưa trên lưới (số liệu mưa tự động (AWS), số liệu mưa vệ tinh (GSMaP)) được đưa về cùng một lưới với mô hình dự báo (phạm vi tính toán được thể hiện trên Hình 1), kết quả dự báo của mô hình số trị được nội suy về điểm trạm bằng phương pháp nội suy điểm gần nhất.

\subsection{Các phương pháp đánh giá kĩ năng dụ báo mưa}

Nghiên cứu đưa ra các kết quả đánh giá dựa trên việc tính toán các chỉ số kĩ năng chi tiết theo khoảng phân cấp mưa (ví dụ trong khoảng $25-50 \mathrm{~mm} / 24 \mathrm{~h}$ ) và theo ngưỡng mưa (ví dụ lớn hơn $25 \mathrm{~mm} / 24 \mathrm{~h}$ ) thực hiện thống kê tại các trạm quan trắc Synop (đánh giá trên trạm) và thực hiện thống kê trên lưới bao phủ toàn bộ khu vực Bắc Bộ (đánh giá theo không gian). Các đánh giá tập trung vào mô hình quy mô toàn cầu IFS, mô hình quy mô khu vực WRF3kmIFS với điều kiện biên IFS độ phân giải $3 \mathrm{~km}$ và mô hình quy mô khu vực có đồng hóa số liệu WRF3kmIFS-DA. Nghiên cứu đánh giá kết quả dự báo lượng mưa tích lũy 24 giờ của các mô hình IFS, WRF3kmIFS và WRF3kmIFS-DA cho khu vực Bắc Bộ giai đoạn tháng 4 đến tháng 12 năm 2020. 


\subsubsection{Phương pháp tính các chỉ số kĩ năng dự báo mưa tại trạm quan trắc}

Việc áp dụng các chỉ số đánh giá cho biến dự báo liên tục dựa trên các chỉ số như sai số trung bình tuyệt đối hay sai số trung bình quân phương để đánh giá kỹ năng dự báo mưa là không phản ánh hết khả năng của mô hình. Bởi bản chất của các dự báo mưa bao gồm cả dự báo pha, tức là xảy ra hay không xảy ra, do đó bộ số liệu mưa dự báo và quan trắc sẽ tuân theo quy luật phân bố nhị phân thay vì phân bố chuẩn cho biến liên tục, chi tiết phân loại trong Bảng 1 (đại lượng $\mathrm{A}$ là tổng số lần dự báo thành công (dự báo đúng hiện tượng có xảy ra), $\mathrm{B}$ là tổng số lần dự báo sót (dự báo không xảy ra hiện tượng có xảy ra), C là tổng số lần dự báo khống (dự báo xảy ra hiện tượng không xảy ra) và $\mathrm{D}$ là tổng số lần dự báo đúng của hiện tượng không xảy ra).Các chỉ số kĩ năng bao gồm BIAS, POD, FAR, TS (tên gọi khác là CSI), ETS sẽ được sử dụng trong nghiên cứu ứng với từng khoảng phân cấp ngưỡng mưa cụ thể [13], minh hoạ trong Hình 3 (trái). Khi đó công thức cho chỉ số TS cho phân cấp mưa thứ i sẽ có dạng:

$$
\mathrm{TS}_{\mathrm{i}}=\frac{\mathrm{n}\left(\mathrm{F}_{\mathrm{i}}, \mathrm{O}_{\mathrm{i}}\right)}{\mathrm{N}\left(\mathrm{F}_{\mathrm{i}}\right)+\mathrm{N}\left(\mathrm{O}_{\mathrm{i}}\right)-\mathrm{n}\left(\mathrm{F}_{\mathrm{i}}, \mathrm{O}_{\mathrm{i}}\right)}
$$

Trong đó $\mathrm{n}\left(\mathrm{F}_{\mathrm{i}} \mathrm{O}_{\mathrm{i}}\right)$ là số lượng dự báo thuộc phân cấp thứ i có quan trắc trong phân cấp thứ $\mathrm{i}$ (hay số dự báo đúng với quan trắc trong phân cấp thứ i); $\mathrm{N}\left(\mathrm{O}_{\mathrm{i}}\right)$ là tổng số quan trắc phân cấp thứ $\mathrm{i} ; \mathrm{N}\left(\mathrm{F}_{\mathrm{i}}\right)$ là tổng số dự báo phân cấp thứ i.

Bảng 1. Bảng phân loại tần xuất cho biến dự báo dạng nhị phân.

\begin{tabular}{cccc}
\hline & & \multicolumn{3}{c}{ Quan trắc } \\
\cline { 3 - 4 } & & Có & Không \\
\hline \multirow{2}{*}{ Dự báo } & Có & $\mathrm{A}$ & $\mathrm{B}$ \\
& Không & $\mathrm{C}$ & $\mathrm{D}$ \\
\hline
\end{tabular}

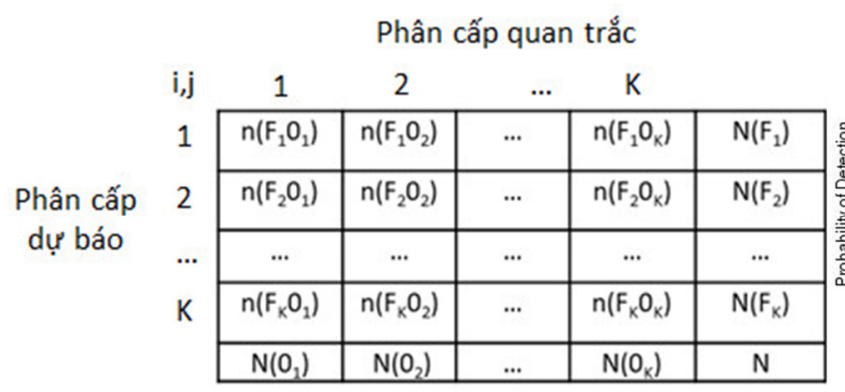

(a)

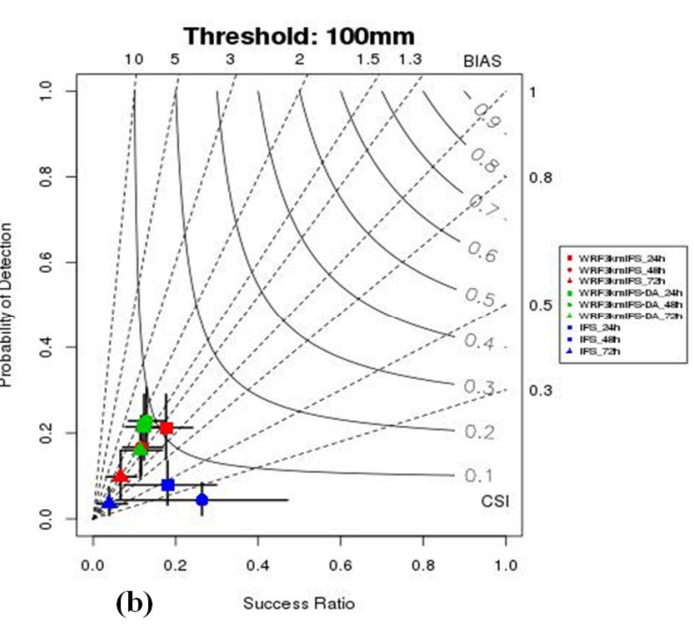

(b)

Hình 3. Minh hoạ bảng đa cấp (a) và biểu đồ đánh giá kĩ năng tổng hợp (b).

Ngoài việc phân tích riêng lẻ các chỉ số kĩ năng, biểu đồ đánh giá kĩ năng tổng hợp (performance diagram) thể hiện mối tương quan hình học giữa các chỉ số POD, FAR, CSI/TS và Bias [14], minh hoạ trong Hình 3 phải. Khoảng tin cậy (Confidence Interval) của các chỉ số kĩ năng được xác định dựa trên phương pháp gieo nhiễu ngẫu nhiên (boottraps) để cho thấy mức độ biến động, độ ổn định của dự báo. Từ vị trí của mô hình trong biểu đồ so với tham chiếu cho phép hình dung được độ chính xác của mô hình. Dự báo hoàn hảo khi nằm ở phía trên bên phải của biểu đồ. Sự sai lệch theo một hướng cụ thể biểu hiện sự khác biệt giữa xác suất phát hiện hiện tượng (POD, trục thẳng đứng bên phải) và tỉ lệ dự báo thành công 
(Success Ratio, bằng 1-FAR, trục ngang dưới), BIAS (đường gạch chéo ứng với các giá trị tại trục ngang trên và trục thẳng đứng bên phải) và chỉ số $\mathrm{CSI} / \mathrm{TS}$ (đường cong liền kèm giá trị đẳng mức).

\subsubsection{Phương pháp đánh giá kĩ năng dự báo mưa theo không gian lưới}

Các phương pháp đánh giá truyền thống chỉ nhắm đến sự phù hợp chính xác giữa dự báo và quan trắc, do đó nó sẽ bỏ qua sự thay đổi theo không gian của sản phẩm dự báo. Cách tiếp cận dựa trên phương pháp xác minh vùng lân cận đối với đánh giá điểm kỹ năng dự báo cho các ngưỡng cụ thể và thực hiện các cửa sổ không gian khác nhau sẽ cho phép xác định các ngưỡng mà mô hình cho chất lượng dự báo cao nhất. Chỉ số kĩ năng phân số (Fractional Skill Score) được dùng trong đánh giá xác suất dự báo mưa vượt ngưỡng hoặc dưới ngưỡng nhất định đối với một cửa sổ không gian nhất định [15-18]. FSS được sử dụng rộng rãi trong việc đánh giá dự báo định lượng mưa [19-20]. Chỉ số FSS phù hợp để đánh giá dự báo trong trường hợp độ phân giải cao (độ phân giải ngang dưới 10 km).

Giả sử trường quan trắc và dự báo có kích thước là $\mathrm{NX} \times \mathrm{NY}$ (với $\mathrm{NX}$ và $\mathrm{NY}$ lần lượt là số điểm lưới theo phương bắc-nam, đông-tây). Giá trị quan trắc và dự báo tại mỗi ô lưới được kí hiệu tương ứng là $\mathrm{MO}_{\mathrm{i}, \mathrm{j}}$ và $\mathrm{MF}_{\mathrm{i}, \mathrm{j}}($ với $\mathrm{i}=1,2, \ldots, \mathrm{NX} ; \mathrm{j}=1,2, \ldots, \mathrm{NY})$. Để thực hiện tính toán giá trị chỉ số FSS, chuyển đổi trường giá trị sang trường nhị phân, kí hiệu giá trị nhị phân tại ô lưới của quan trắc của dự báo lần lượt là $\mathrm{PO}_{\mathrm{i}, \mathrm{j}}, \mathrm{PF}_{\mathrm{i}, \mathrm{j}}($ với $\mathrm{i}=1,2, \ldots, \mathrm{NX} ; \mathrm{j}=1,2, \ldots, \mathrm{NY})$ và được xác định bởi điều kiện sau:

$$
\begin{array}{cc}
\mathrm{PF}_{\mathrm{i}, \mathrm{j}}=1: \text { Nếu } \mathrm{MF}_{\mathrm{i}, \mathrm{j}} \geq \text { ngưỡng } & \mathrm{PF}_{\mathrm{i}, \mathrm{j}}=0: \text { Nếu } \mathrm{MF}_{\mathrm{i}, \mathrm{j}}<\text { ngưỡng } \\
\mathrm{PO}_{\mathrm{i}, \mathrm{j}}=1: \text { Nếu } \mathrm{MO}_{\mathrm{i}, \mathrm{j}} \geq \text { ngưỡng } & \mathrm{PO}_{\mathrm{i}, \mathrm{j}}=0: \text { Nếu } \mathrm{MO}_{\mathrm{i}, \mathrm{j}}<\text { ngưỡng }
\end{array}
$$

Tính toán giá trị phân số quan trắc, phân số dự báo cho từng ô lưới theo phạm vi không gian (vùng lân cận) kích thước $\mathrm{K} x \mathrm{~K}$ điểm lưới, bán kính vùng lân cận là $\mathrm{k}$ với $\mathrm{k}=(\mathrm{K}-1) / 2$. Kí hiệu $\mathrm{O}_{\mathrm{i}, \mathrm{j}}$ và $\mathrm{F}_{\mathrm{i}, \mathrm{j}}$ (với $\mathrm{i}=1,2, \ldots, \mathrm{N}_{\mathrm{X}} ; \mathrm{j}=1,2, \ldots, \mathrm{N}_{\mathrm{Y}}$ ) tương ứng là giá trị phân số thực tế và dự báo tại ô lưới sau khi được tính toán với một phạm vi không gian cho trước. Giá trị $\mathrm{O}_{\mathrm{i}, \mathrm{j}}$ và $\mathrm{F}_{\mathrm{i}, \mathrm{j}}$ (vị trí ô lưới thuộc hàng thứ $i$, cột thứ $j$ ) được tính bởi công thức:

$$
\begin{aligned}
& O_{(K) i, j}=\frac{1}{K \times K} \sum_{m=(i-k)}^{i+k} \sum_{n=(j-k)}^{i+k} P O_{m, n} \\
& F_{(K) i, j}=\frac{1}{K \times K} \sum_{m=(i-k)}^{i+k} \sum_{n=(j-k)}^{i+k} P F_{m, n}
\end{aligned}
$$

Với những ô lưới không phải là trung tâm của bất kì phạm vi không gian nào, $\mathrm{O}_{\mathrm{i}, \mathrm{j}}$ và $\mathrm{F}_{\mathrm{i}, \mathrm{j}}$ sẽ nhận giá trị bằng 0 . Khi đó, chỉ số FSS đối với phạm vi không gian $\mathrm{K} x \mathrm{~K}$ được tính theo công thức:

$$
\mathrm{FSS}_{(\mathrm{K})}=1-\frac{\frac{1}{\mathrm{~N}_{\mathrm{X}} \times \mathrm{N}_{\mathrm{Y}}} \sum_{\mathrm{i}=1}^{\mathrm{N}_{\mathrm{Y}}} \sum_{\mathrm{j}=1}^{N_{\mathrm{Y}}}\left[\mathrm{O}_{(\mathrm{K}) \mathrm{i}, \mathrm{j}}-\mathrm{F}_{(\mathrm{K}) \mathrm{i}, \mathrm{j}}\right]^{2}}{\frac{1}{\mathrm{~N}_{\mathrm{X}} \times \mathrm{N}_{\mathrm{Y}}}\left[\sum_{\mathrm{i}=1}^{N_{\mathrm{Y}}} \sum_{\mathrm{j}=1}^{N_{\mathrm{Y}}} \mathrm{O}^{2}{ }_{(\mathrm{K}) \mathrm{i}, \mathrm{j}}+\sum_{\mathrm{i}=1}^{N_{\mathrm{Y}}} \sum_{\mathrm{j}=1}^{N_{\mathrm{Y}}} \mathrm{F}^{2}{ }_{(\mathrm{K}) \mathrm{i}, \mathrm{j}}\right]}
$$

Hình 4 minh hoạ về việc chuyển đổi giá trị mưa dự báo theo từng ngưỡng về dạng nhị phân để tính toán chỉ số FSS (ví dụ với quy mô không gian là 3 ô lưới , ô lưới vàng sẽ thực hiện rà trên toàn bộ miền tính để tính toán giá trị phân số mới cho mỗi ô lưới là giá trị trung bình của các ô lưới trong phạm vi lưới vuông $3 \times 3$, những điểm không thể tồn tại ô lưới vàng sẽ có giá trị phân số bằng 0 ). Hình $4 \mathrm{c}$ minh hoạ về sự thay đổi của chỉ số FSS theo từng mức độ chi tiết về mặt không gian được đánh giá. Giá trị FSS càng cao (tối ưu nhất là 1) ứng với việc dữ liệu lưới mô hình dự báo phù hợp hoàn toàn với dữ liệu lưới quan trắc tại các ngưỡng đánh giá cụ thể. Việc đánh giá bằng chỉ số FSS cũng cho phép xác địinh được mức độ tin cậy theo không gian của từng mô hình qua đó đưa ra được dự báo theo cấp tỉnh, vùng phù hợp. Ở một qui mô không gian cụ thể, nếu FSS có giá trị trên 0,55 sẽ được xem là mô hình có kĩ năng theo không gian đó (mức độ phù hợp hiệu dụng). 


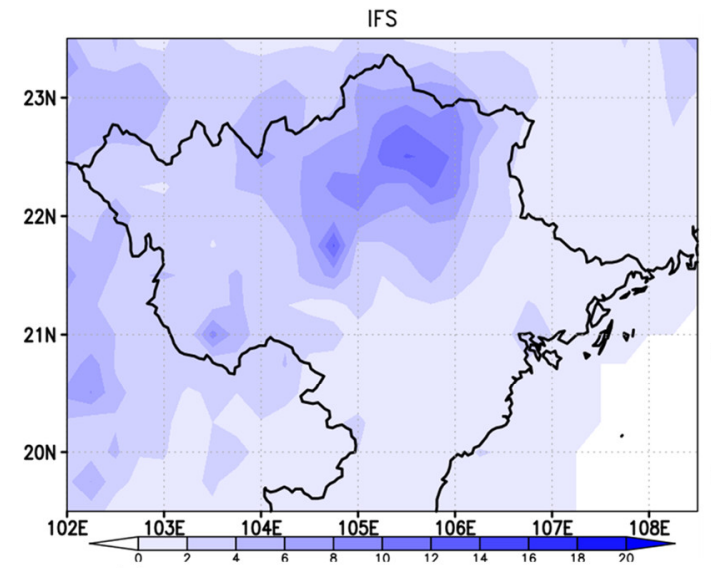

(a)

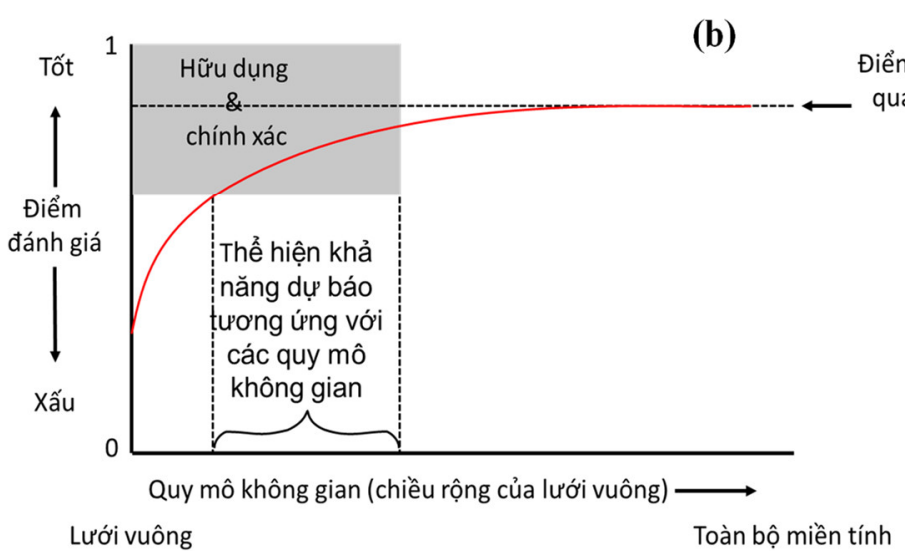

IFS

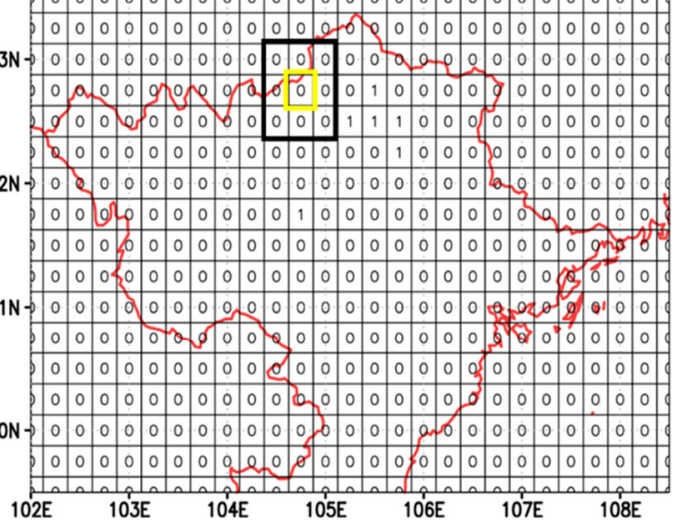

Điểm số xác định liên quan đến sai số hệ thống bias

Hình 4. Minh hoạ trường dự báo mưa từ IFS (a) được chuyển đổi sang trường nhị phân ở ngưỡng $10 \mathrm{~mm} / 6 \mathrm{~h}(\mathrm{~b})$ để xác định chỉ số FSS và minh họa biến đổi của chỉ số kĩ năng FSS theo từng mức độ không gian (c).

\section{Kết quả và thảo luận}

\section{1. Đánh giá kết quả dụ báo tại trạm}

Hình 5 minh họa biểu đồ đánh giá kĩ năng tổng hợp cho dự báo lượng mưa tích lũy 24 giờ trên các ngưỡng $1 \mathrm{~mm}, 5 \mathrm{~mm}, 10 \mathrm{~mm}, 20 \mathrm{~mm}, 50 \mathrm{~mm}$ và $100 \mathrm{~mm}$ với các hạn dự báo $24 \mathrm{~h}$, $48 \mathrm{~h}$ và $72 \mathrm{~h}$ cho khu vực Bắc Bộ. Nhìn chung, tỉ lệ dự báo thành công, tỉ lệ phát hiện hiện tượng, chỉ số kĩ năng TS và độ tin cậy của các mô hình đều giảm khi ngưỡng lượng mưa tăng (mức tin cậy của kết quả dự báo từ mô hình IFS nhỏ nhất trong các mô hình). Ở các ngưỡng 1 $\mathrm{mm}, 5 \mathrm{~mm}$ và $10 \mathrm{~mm}$, mô hình IFS có chỉ số phát hiện POD cao nhất tại cả 3 hạn dự báo (đặc biệt hạn 72h) tuy nhiên chỉ số BIAS lại dao động từ 2 đến 3.5 (cao nhất trong các mô hình), mô hình độ phân giải cao có đồng hóa số liệu WRF3kmIFS-DA xác suất phát hiện hiện tượng nhỉnh hơn so với mô hình không có đồng hóa WRF3kmIFS. Tại các ngưỡng mưa lớn hơn, tỉ lệ dự báo thành công của IFS lớn nhất nhưng giá trị POD lại nhỏ nhất, chỉ số BIAS giảm khi ngưỡng mưa tăng. Giá trị chỉ số POD của mô hình WRF3kmIFS-DA lớn hơn so với WRF3kmIFS (dự báo của 2 mô hình đều tốt nhất tại hạn 24h) và lớn nhất đối với các ngưỡng mưa trên $20 \mathrm{~mm} / 24 \mathrm{~h}$. Tại tất cả các ngưỡng mưa, giá trị BIAS của các mô hình khu vực độ phân giải cao đều nằm trong khoảng từ 1 đển 1.5. Chỉ số kĩ năng TS của 3 mô hình lớn nhất tại hạn dự báo $24 \mathrm{~h}$ tại tất cả các ngưỡng mưa. Đối với lượng mưa tích lũy 24 giờ trên $50 \mathrm{~mm}$, mô hình WRF3kmIFS và WRF3kmIFS-DA luôn có chỉ số kĩ năng TS lớn hơn so với mô hình IFS tại cả 3 hạn dự báo. 

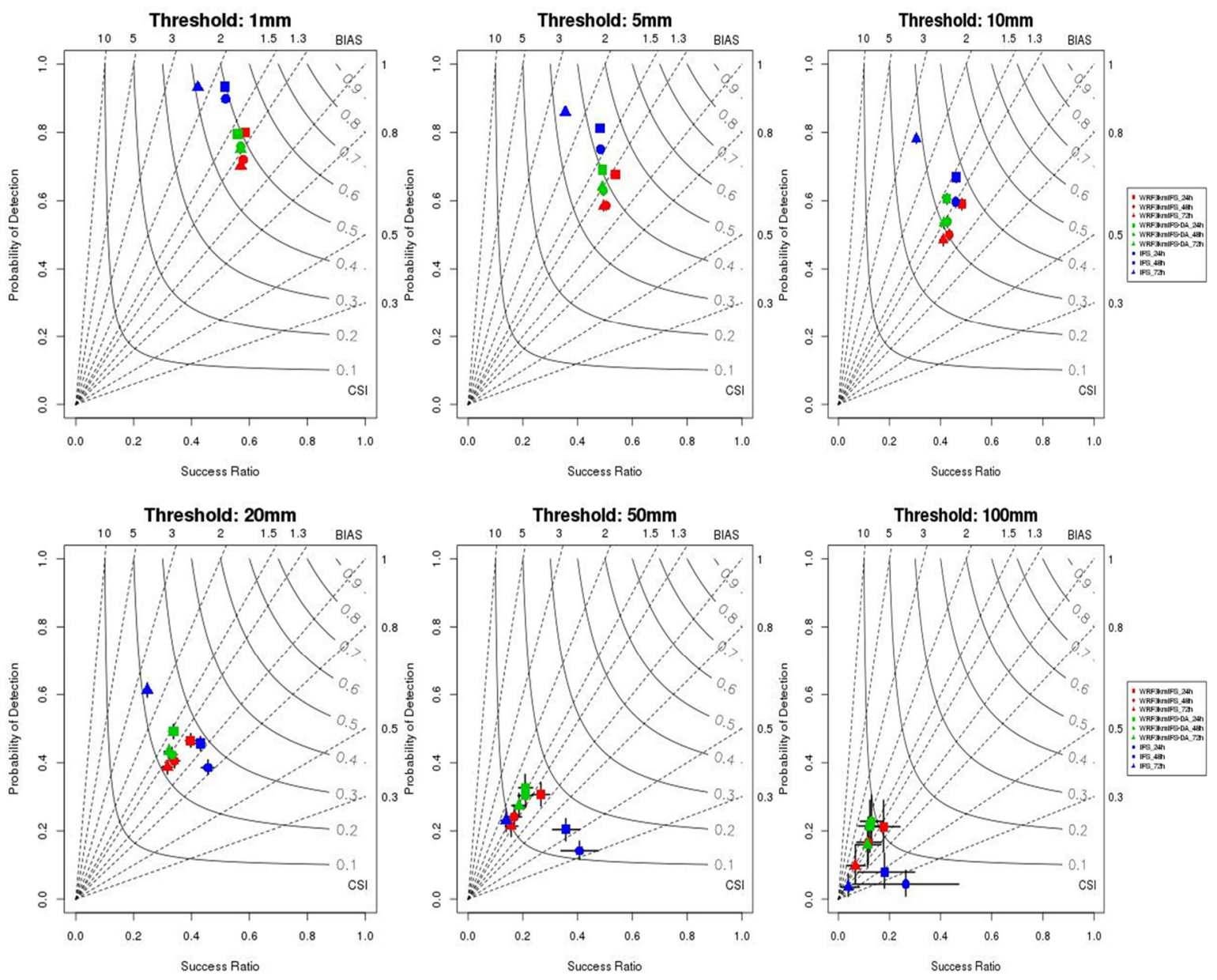

Hình 5. Biểu đồ đánh giá kĩ năng tổng hợp đối với lượng mưa tích lũy 24 giờ tại các ngưỡng mưa khác nhau. Kí hiệu màu xanh da trời, đỏ, xanh lá cây ứng với mô hình IFS, WRF3kmIFS và WRF3kmIFS-DA tại các hạn dự báo $24 \mathrm{~h}, 48 \mathrm{~h}$ và $72 \mathrm{~h}$.

Phân tích mức độ chính xác trong việc dự báo đúng lượng mưa quan trắc rơi vào từng phân cấp mưa cụ thể, qua đó phản ảnh đúng tỉ lệ dự báo đúng so với tổng mẫu dự báo đánh giá, trong Hình 6 đưa ra kết quả đánh giá dựa trên chỉ số kĩ năng TS (giá trị tối ưu bằng 1 ứng khi dự báo từ mô hình đúng hoàn toàn so với quan trắc) và Bảng 2 trình bày giá trị chi tiết của các chỉ số kĩ năng (BIAS, POD, ETS, TS), các kết quả cho thấy:

- Ở hạn dự báo $24 \mathrm{~h}$ : ngoài phân cấp mưa dưới $1 \mathrm{~mm} / 24 \mathrm{~h}$ (các mô hình dự báo xác suất xuất hiện hiện tượng đúng phổ biến khoảng 80 đến 90\%), ở ngưỡng 10-25 mm/24h các mô hình cho khả năng dự báo đúng cao nhất với tỉ lệ khoảng $38 \%$ trong khi ở các ngưỡng trên 25 $\mathrm{mm} / 24 \mathrm{~h}$ đạt khoảng $8-25 \%$. Tại hạn dự báo này, chỉ số BIAS của mô hình IFS dao động từ 1 đến 2,5 với lượng mưa dưới $50 \mathrm{~mm} / 24 \mathrm{~h}$ và khoảng 0,5 với các ngưỡng còn lại, trong khi đó mô hình khu vực độ phân giải cao WRF3kmIFS và WRF3kmIFS-DA luôn dao động từ 1 đến 1,5. Mô hình IFS có chỉ số kĩ năng TS cao nhất tại ngưỡng 10-25 mm/24h trong khi đó với các ngưỡng mưa lớn trên $100 \mathrm{~mm} / 24 \mathrm{~h}$, mô hình WRF3kmIFS cho kết quả tốt nhất, chỉ số phát hiện tăng lên $20 \%$ so với mô hình toàn cầu (chỉ số phát hiện POD chỉ khoảng $7 \%$ ).

- Ở hạn dự báo $48 \mathrm{~h}$ và $72 \mathrm{~h}$, xu thế sai số khá tương đồng với chỉ số TS lớn nhất tại phân cấp mưa $10-25 \mathrm{~mm} / 24 \mathrm{~h}$, ngoài ngưỡng mưa dưới $1 \mathrm{~mm} / 24 \mathrm{~h}$, xác suất dự báo xuất hiện hiện tượng tại ngưỡng mưa này cao nhất khoảng 30-35\%. Đặc biệt, với các ngưỡng phân cấp mưa lớn (trên $100 \mathrm{~mm} / 24$ với hạn dự báo $48 \mathrm{~h}$; trên $24 \mathrm{~mm} / 24 \mathrm{~h}$ với hạn dự báo $72 \mathrm{~h}$ ) mô hình độ phân giải cao có đồng hóa số liệu cho kết quả dự báo tốt hơn, chỉ số kĩ năng TS cao hơn hẳn so với 2 mô hình IFS và WRF3kmIFS. 


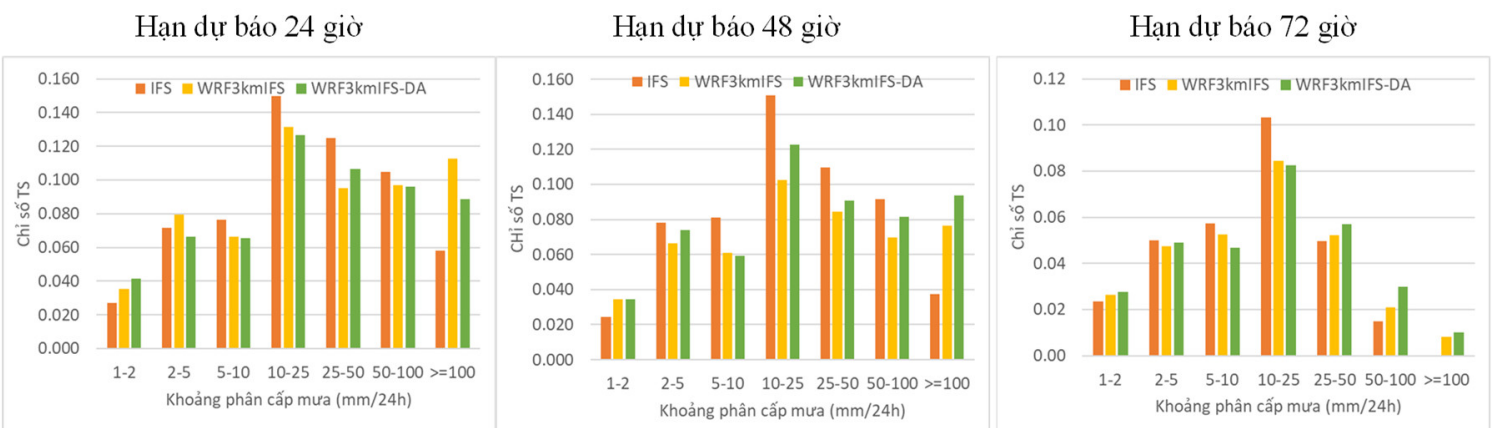

Hình 6. Chỉ số kĩ năng TS đánh giá mức độ dự báo đúng của các mô hình (IFS, WRF3kmIFS, WRF3kmIFS-DA) tại từng khoảng ngưỡng phân cấp mưa. Mẫu đánh giá trong năm 2020, tính trung bình trên khu vực Bắc Bộ, hạn dự báo 24,48 và 72 giờ.

Bảng 2. Chi tiết các chỉ số kĩ năng (BIAS, POD, ETS, TS) của mô hình các mô hình tại từng khoảng ngưỡng phân cấp mưa. Mẫu đánh giá trong năm 2020 cho khu vực Bắc Bộ, hạn dự báo 24, 48 và 72 giờ.

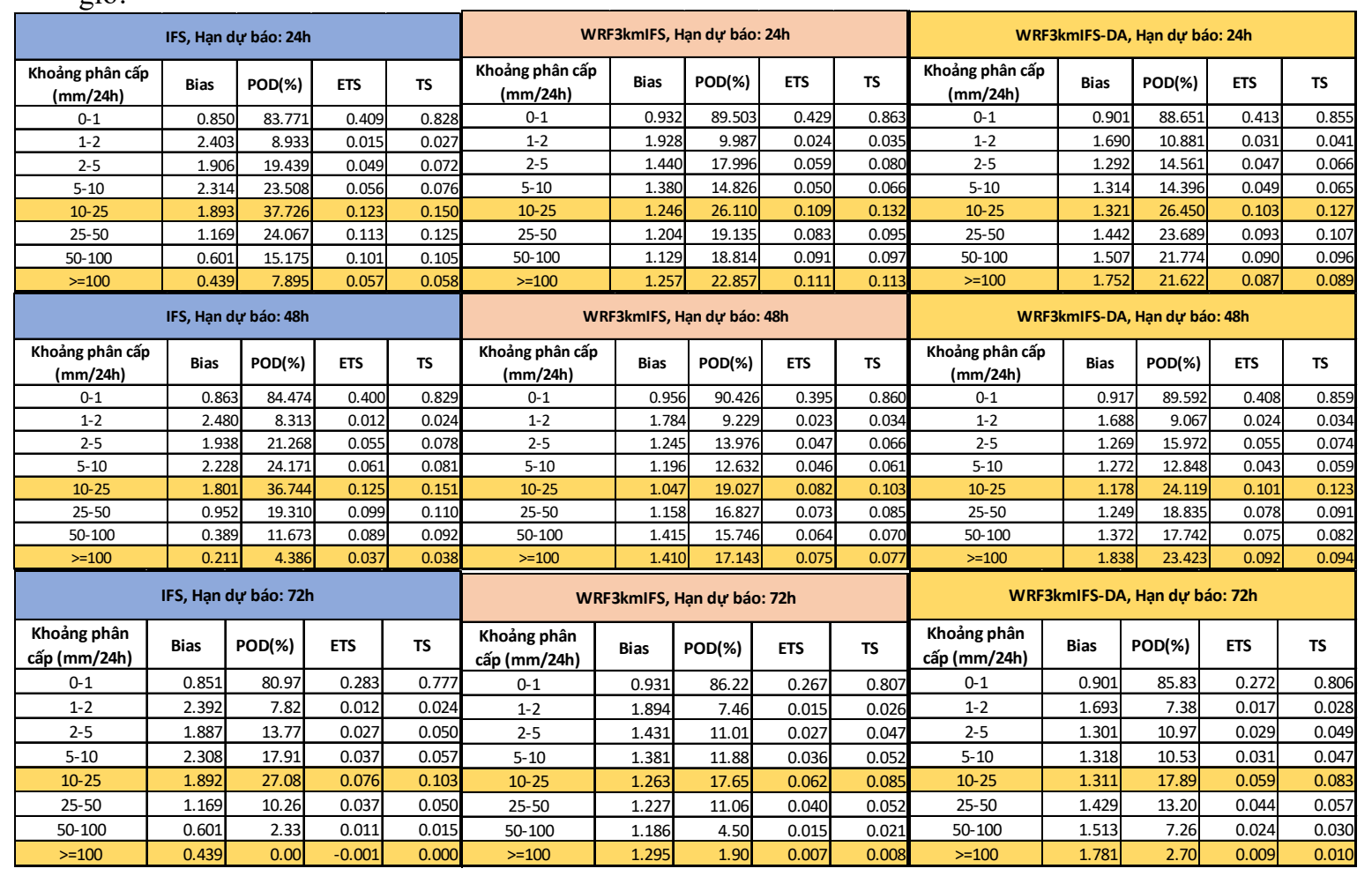

\section{2. Đánh giá kĩ năng dụ báo theo không gian}

Trong nghiên cứu thực hiện đánh giá theo mức độ chi tiết của từng mô hình, số liệu lưới quan trắc đưa về lưới mô hình. Việc so sánh song song cả với số liệu mưa lưới từ vệ tinh và mưa lưới từ quan trắc radar-mưa tự động cho phép xem xét tính khách quan của kết quả đánh giá khi so sánh với bộ số liệu độc lập. Đối với số liệu mưa vệ tinh, các đánh giá thường thiên cao hơn so với thực tế do các giá trị lượng mưa cực trị xác định từ số liệu vệ tinh thường thiên thấp.

Hình 7 thể hiện chi tiết giá trị chỉ số kĩ năng FSS đối với lượng mưa tích lũy 24 giờ tính từ dữ liệu GSMaP và mô hình dự báo. Nhìn chung, giá trị FSS giảm khi ngưỡng mưa tăng và tăng khi vùng lân cận tăng. Tại các ngưỡng mưa dưới $10 \mathrm{~mm} / 24 \mathrm{~h}$, độ phù hợp của dự báo và quan trắc lên đến $50-60 \%$. Tại hạn $24 \mathrm{~h}$ và $72 \mathrm{~h}$, giá trị $\mathrm{FSS}$ từ mô hình WRF3kmIFS nhỉnh hơn 2 mô hình còn lại, thấp nhất đối với IFS. Hạn 48h, mô hình độ phân giải cao có đồng hóa số liệu WRF3kmIFS-DA có chỉ số kĩ năng FSS lớn nhất. Đối với ngưỡng mưa trên 100 
$\mathrm{mm} / 24 \mathrm{~h}$, kết quả dự báo của WRF3kmIFS-DA chính xác nhất tại hạn $24 \mathrm{~h}$, trong khi đó hạn $48 \mathrm{~h}$ và $72 \mathrm{~h}$, mô hình WRF3kmIFS cho kết quả tốt nhất. Mức độ phù hợp hiệu dụng đạt được tại ngưỡng mưa trên $1 \mathrm{~mm} / 24 \mathrm{~h}$ và quy mô hiệu dụng tăng theo hạn dự báo và nhỏ nhất đối với mô hình khu vực độ phân giải cao (WRF3kmIFS và WRF3kmIFS-DA) với quy mô vùng lân cận 9x9 ô lưới (bán kính khoảng $12 \mathrm{~km}$ ).

Giá trị chỉ số kĩ năng FSS từ dữ liệu AWS và mô hình được trình bày cụ thể trên hình 8 . Với ngưỡng lượng mưa dưới $20 \mathrm{~mm} / 24 \mathrm{~h}$, giá trị chỉ số kĩ năng FSS tại 3 hạn dự báo đều lớn nhất với mô hình IFS, mức độ phù hợp giữa dự báo và số liệu quan trắc có bổ sung radar và mưa tự động (AWS) đạt khoảng 50-65\%. Trong khi đó, các ngưỡng mưa trên $20 \mathrm{~mm} / 24 \mathrm{~h}$, FSS từ số liệu dự báo mô hình WRF3kmIFS-DA tốt hơn hẳn so với 2 mô hình còn lại. Đặc biệt với lượng mưa trên $100 \mathrm{~mm} / 24 \mathrm{~h}$, mô hình có đồng hóa cho thấy mức độ phù hợp cao nhất lên đến $20 \%$, tăng khoảng $2 \%$ so với mô hình WRF3kmIFS trong khi mô hình toàn cầu IFS mức độ phù hợp chỉ khoảng 5\%.
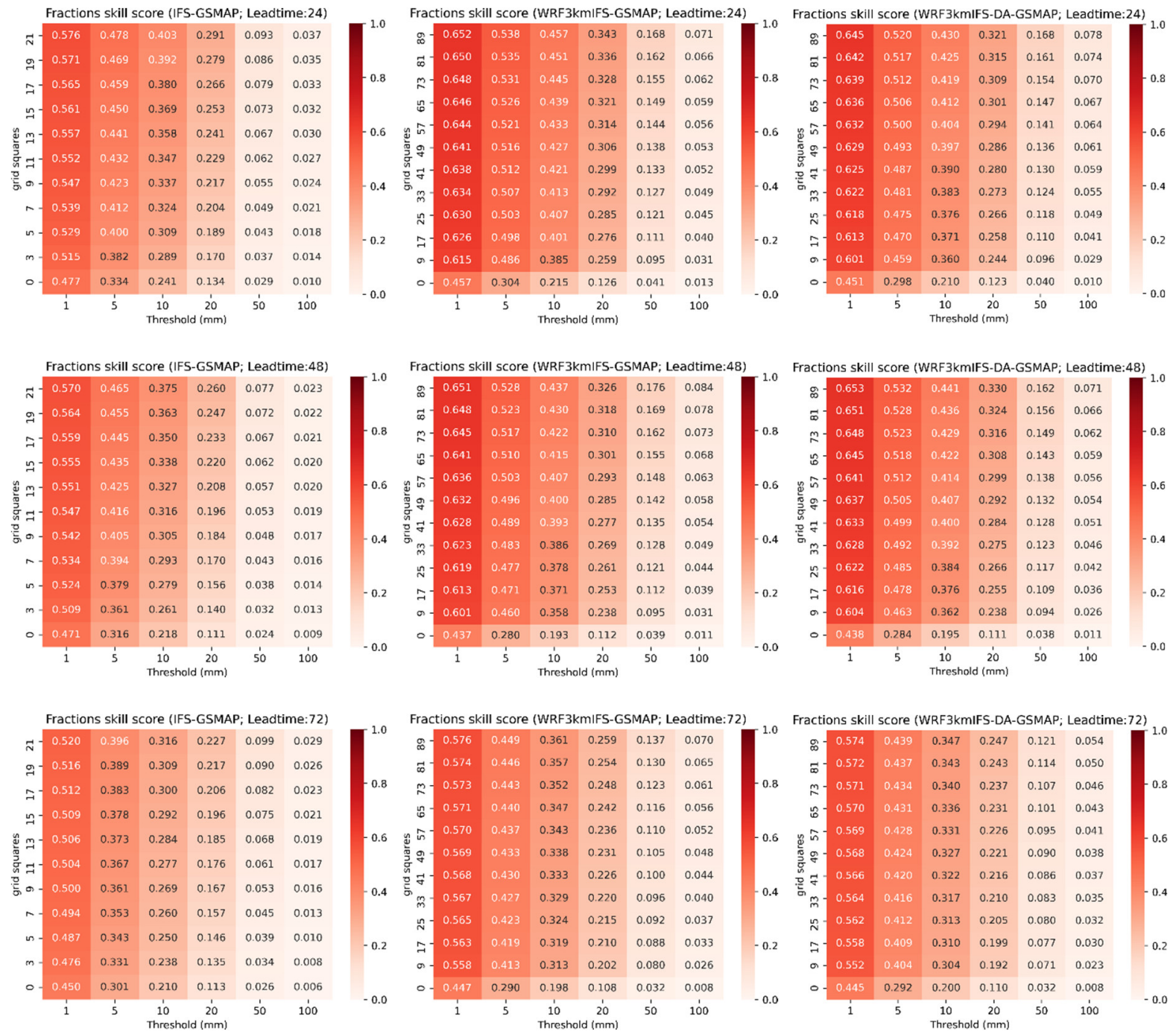

Hình 7. Giá trị chỉ số kĩ năng FSS so với dữ liệu mưa lưới từ vệ tinh (GSMaP) của các mô hình cho khu vực Bắc Bộ cho dự báo lượng mưa tích lũy 24 giờ tại các ngưỡng mưa khác nhau. 

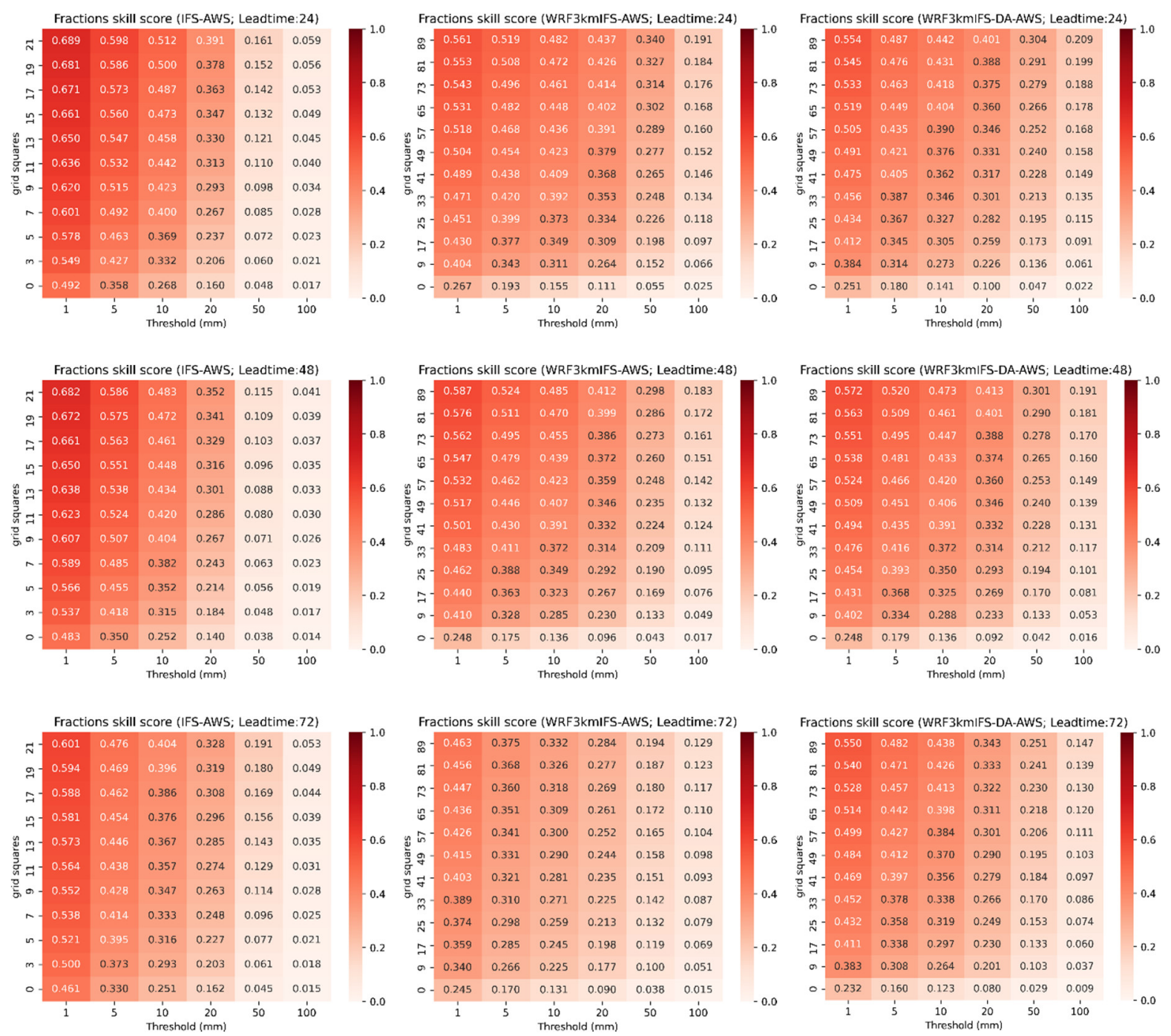

Hình 8. Giá trị chỉ số kĩ năng FSS so vơi dữ liệu mưa lưới từ quan trắc radar-tự động (AWS) của các mô hình cho khu vực Bắc Bộ cho dự báo lượng mưa tích lũy 24 giờ tại các ngưỡng mưa khác nhau.

\section{Kết luận}

Nghiên cứu đã trình bày các kết quả đánh giá kết quả dự báo mưa của mô hình IFS, WRF3kmIFS và WRF3kmIFS-DA trong năm 2020 cho khu vực Bắc Bộ. Phương pháp đánh giá theo không gian dựa trên chỉ số kĩ năng FSS đã được thực hiện với các dữ liệu mưa quan trắc trên lưới từ vệ tinh của Nhật Bản $(\mathrm{GSMaP})$ và dữ liệu mưa trên lưới được thiết lập từ dữ liệu quan trắc ước lượng mưa radar-vệ tinh-quan trắc mưa tự động. Các chỉ số đánh giá kĩ năng (POD, BIAS, TS) theo phương pháp truyền thống và được mở rộng theo từng phân cấp mưa chi tiết kết hợp biểu đồ đánh giá kĩ năng tổng hợp đã được thực hiện song song trên các vị trị trạm của khu vực Bắc Bộ.

Mô hình IFS có chỉ số phát hiện POD cao hơn ở những ngưỡng mưa nhỏ (dưới 20 $\mathrm{mm} / 24 \mathrm{~h}$ ). Trong khi đó, ở các ngưỡng mưa lớn hơn mô hình độ phân giải cao WRF3kmIFS cho kĩ năng dự báo tốt hơn rõ rệt khi xét theo cả trạm và không gian. Đặc biệt với các ngưỡng lượng mưa tích lũy 24 giờ trên $50 \mathrm{~mm}$, mô hình có ĐHSL WRF3kmIFS-DA kĩ năng dự báo tốt hơn đáng kể. Các kết quả đánh giá chi tiết về mặt không gian cho thấy độ phân giải hiệu dụng của của các mô hình đều rất thấp cho ngưỡng mưa lớn hơn $20 \mathrm{~mm} / 24 \mathrm{~h}$ (không đạt được FSS > 0,55), mặc dù kĩ năng dự báo theo không gian có tăng trong WRF3kmIFS và WRF3kmIFS-DA nhưng vẫn thấy rõ việc hạn chế trong khả năng cung cấp được dự báo định lượng ở quy mô chi tiết cho khu vực Bắc Bộ. 
Các kết quả đánh giá cho thấy kĩ năng dự báo định lượng cho khu vực Bắc Bộ còn thấp. Mặc dù vậy, mô hình phân giải cao kết hợp đồng hóa số liệu của bằng phương pháp biến phân 3 chiều (3DVAR) đã tăng được kĩ năng dự báo ở các ngưỡng mưa lớn ( $>50 \mathrm{~mm} / 24 \mathrm{~h})$ trong hạn 1-3 ngày và qua đó cho phép bổ sung thông tin mang tính chất định lượng-cực trị bên cạnh sản phẩm dự báo của mô hình IFS.

Đóng góp của tác giả: Xây dựng ý tưởng nghiên cứu: C.T., D.D.T.; Lựa chọn phương pháp nghiên cứu: D.D.T., N.T.N.; Xử lý số liệu: N.T.N., M.K.H.; Phân tích mẫu: N.T.N., M.K.H.; Lấy mẫu: N.T.N., M.K.H.; Viết bản thảo bài báo: D.D.T., N.T.N., M.K.H.; Chỉnh sửa bài báo: C.T., D.D.T.

Lời cam đoan: Tập thể tác giả cam đoan bài báo này là công trình nghiên cứu của tập thể tác giả, chưa được công bố ở đâu, không được sao chép từ những nghiên cứu trước đây; không có sự tranh chấp lợi ích trong nhóm tác giả.

\section{Tài liệu tham khảo}

1. Watson, P.A.G.; Christensen, H.M.; Palmer, T.N. Does the ECMWF IFS Convection Parameterization with Stochastic Physics Correctly Reproduce Relationships between Convection and the Large-Scale State? J. Atmos. Sci. 2015, 72(1), 236-242.

2. Kalnay, E. Atmospheric modeling, data assimilation and predictability. Cambridge University Press, Cambridge, 2003.

3. Bá, T.Đ.; Hòa, V.V.; Trí, Đ.Q. Đánh giá chất lượng dự báo mưa hạn ngắn của mô hình IFS trên khu vực Bắc Trung Bộ. Tạp chí Khí tượng Thủy văn 2019, 697, 33-43.

4. Hòa, V.V. Nghiên cứu so sánh kỹ năng dự báo mưa lớn khu vực miền Trung và Tây Nguyên của một số mô hình toàn cầu. Tạp chí Khí tượng Thưy văn 2016, 667, 1-8.

5. Thủy, N.T.; Hòa, V.V.; Tiến, T.T.; Hưng, M.K. Đánh giá chất lượng dụ báo mưa lớn của hệ thống dự báo tổ hợp hạn ngắn trên khu vực đồng bằng Bắc Bộ. Tạp chi Khi twợng thüy văn 2018, 696, 42-53.

6. Ngọc, L.A.; Tín, N.V.; Phát, T.N.; Hồng, N.V. Đánh giá khẳ năng dự báo thời tiết của mô hình WRF (Weather, Research and Forecasting) cho khu vực Nam Bộ. Tạp chi Khí tượng Thủy văn 2019, 708, 55-63.

7. Thức, T.D.; Thanh, C. Thử nghiệm đồng hóa dữ liệu radar trong mô hình WRF để dự báo mưa lớn cho khu vực Thành phố Hồ Chí Minh. Tạp chí Khoa hoc ĐHQGHN: Các Khoa học Trái Đất và Môi trương 2018, 34(1S), 59-70.

8. Tiến, D.Đ.; Tăng, B.M.; Hòa, V.V.; Vui, P.T.; Đức, T.A.; Hưng, M.K.; Linh, N.M. Đánh giá tác động của đồng hóa số liệu và điều kiện biên đến kết quả dự báo mưa lớn từ mô hình WRF cho khu vực tại miển Trung và Tây Nguyên. Tạp chi Khi tuợng thủy văn 2014, 647, 25-30.

9. Khiêm, M.V.; Woo, W.C.; Wong, W.K.; Yeung S.L.; Tiến, D.Đ.; Hưng, M.K.; Quân, Đ.Đ.; Dung, P.T.P.; Nga, N.T.; Trang. C.T.H. Case Study of using The Blending Radar-Numerical Weather Prediction Product in Nowcasting. VNU Journal of Science: Earth and Environmental Sciences 2021, 37(3), 1-8.

10. Saito, K.; Hung, M.K.; Hung, N.V.; Vinh, N.Q.; Tien, D.D. Heavy rainfall in central Viet Nam in December 2018 and modification of precipitation nowcasting at VNMHA. VN J. Hydrometeorol. 2020, 5, 65-79.

11. Hung, M.K.; Saito, K.; Khiem, M.V.; Tien, D.D.; Hung, N.V. Application of GSMaP Satellite data in precipitation estimation and nowcasting: evaluations for October 2019 to January 2020 period for Vietnam. VN J. Hydrometeorol. 2020, 5, 80-94.

12. Tiến, D.Đ.; Cường, H.Đ.; Hưng, M.K.; Lâm, H.P. Vai trò của sai số mô hình trong bài toán đồng hóa số liệu dựa trên phương pháp biến phân: thử nghiệm với mô hình 
phân giải cao WRF-ARW và dự báo mưa lớn trong trên khu vực Bắc Bộ. Tạp chí Khi tương Thủy văn 2019, 699, 42-49.

13. Wilks, D.S. Statistical Methods in the Atmospheric Sciences. $2^{\text {nd }}$ ed. Academic Press. 2006, pp. 627.

14. Roebber, P.J. Visualizing Multiple Measures of Forecast Quality. Weather Forecasting 2009, 24(2), 601-608.

15. Zhao, B.; Zhang, B. Assessing Hourly Precipitation Forecast Skill with the Fractions Skill Score. J. Meteorol. Res. 2018, 32, 135-145.

16. Roberts, N.M.; Lean, H.W. Scale-Selective Verification of Rainfall Accumulations from High-Resolution Forecasts of Convective Events. Monthly Weather Review. 2008, 136(1), 78-97.

17. Mittermaier, M.; Roberts, N.; Thompson, S.A. A long-term assessment of precipitation forecast skill using the Fractions Skill Score. Meteor. Appl. 2013, 20, 176-186.

18. Skok, G.; Roberts, N. Analysis of Fractions Skill Score properties for random precipitation fields and ECMWF forecasts. Quart. J. Roy. Meteor. Soc. 2016, 142, 2599-2610.

19. Baldauf, M.; Seifert, A.; Förstner, J.; Majewski, D.; Raschendorfer, M.; Reinhardt, T. Operational convective-scale numerical weather prediction with the COSMO model: Description and sensitivities. Mon. Wea. Rev. 2011, 139, 3887-3905.

20. Herman, G.R.; Schumacher, S. Extreme precipitation in models: An evaluation. Wea. Forecasting 2016, 31, 1853-1879.

\title{
Verification of quantitative rainfall forecast from IFS and WRF model for the northern region of Viet Nam
}

\author{
Nguyen Thi Nga ${ }^{1}$, Cong Thanh ${ }^{2}$, Mai Khanh Hung ${ }^{1}$, Du Duc Tien ${ }^{*}$ \\ ${ }^{1}$ National Center for Hydrometeorological Forecasting; duductien@gmail.com; \\ maikhanhhung18988@gmail.com; hongnga12897@gmail.com \\ ${ }^{2}$ Faculty of Meteorology, Hydrology, and Oceanography, VNU University of Science, \\ Vietnam National University, Hanoi; congthanh1477@gmail.com
}

\begin{abstract}
This research aims to validate heavy rainfall forecasting over northern Vietnam of IFS (ECMWF) and the Weather Research and Forecasting with the Advanced Research dynamical solver (WRF-ARW) models from 4-12/2020. Typical skill scores are calculated based on the surface observation data (POD, FAR, BIAS, CSI/TS) and the performance diagram is used for combination exploitation based on those skill scores. The spatial verifications are carried out using the fraction skill score (FSS) and grid rainfall observations (both from the satellite-based GSMaP product and aws-radar-based). Both skill validations of station-based and spatial-based show low skills of models for high thresholds of $24 \mathrm{~h}$ accumulated rainfall forecast. But in general, the advanced skill forecast for high thresholds ( $>50 \mathrm{~mm} / 24 \mathrm{~h}$ ) from high-resolution regional models WRF3kmIFS (WRF-ARW using IFS as boundary conditions) and WRF3kmIFS-DA (WRF3kmIFS with data assimilation).
\end{abstract}

Keywords: Spatial verification; Fraction skill score; Multi-category Contingency Table. 